\title{
Impact of polymer addition, electrolyte, clay and antioxidant on rheological properties of polymer fluid at high temperature and high pressure
}

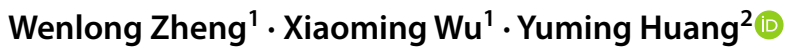

Received: 16 December 2018 / Accepted: 16 July 2019 / Published online: 22 July 2019

(c) The Author(s) 2019

\begin{abstract}
Nowadays, the application of polymer in petroleum industries due to its feasibility with enhancing hole cleaning, less formation damage characteristics of drilling fluids has been particularly advantageous in deep well operation. However, figuring out the influence mechanism of temperature on the rheological behavior of polymer fluids and keeping the excellent rheological regulation at high temperature and high pressure (HTHP) are still serious issues for the mud designers. In this work, the rheological properties of a commonly used drilling fluid polymer treating agent named Driscal-D were tested under HTHP conditions by Fann 50SL rheometer. The effects of polymer addition, electrolyte, clay type and antioxidant on the rheological properties of Driscal-D solution were studied in high-temperature environments. Results showed that the viscosity of the solutions tends to increase with the polymer addition increases, making its pseudoplastic characteristics more noticeable. As the temperature rises, the fluid loses viscosity, causing the polymer solution to evolve from pseudoplastic fluid to Newtonian fluid. The presence of the electrolyte and the oxygen scavenger leads to a decrease in the viscosity of the solution, but in high-temperature environments, the solution adding formate or antioxidant has a higher viscosity retention rate than the pure solution at low shear rates $\left(<50 \mathrm{~s}^{-1}\right)$. The incorporation of the clay in Driscal-D solution enhances the rheological properties, which is beneficial for cuttings transportation. And the dispersion is best described by Herschel-Bulkley model.
\end{abstract}

Keywords Rheological property $\cdot$ Formate $\cdot$ Clay $\cdot$ Polymer fluid $\cdot$ High temperature and high pressure $\cdot$ Herschel-Bulkley model

\section{Introduction}

In oil and gas drilling industries, one of the biggest challenges is controlling the rheological property of drilling fluids, especially in high-temperature and high-pressure (HTHP) environments. It is of crucial importance for precisely calculating the pressure drop in annular, carrying the drilled cuttings to surface and predicting the equivalent circulation density, as well as controlling the bottom hole

Yuming Huang

huangyuming718@126.com

1 School of Engineering, China University of Geosciences (Wuhan), Wuhan 430074, China

2 College of Geoscience and Surveying Engineering, China University of Mining \& Technology (Beijing), Beijing 100083, China pressure (Fisk and Jamison 1989; Bland et al. 2006; AlAzani et al. 2019; Abdelgawad et al. 2019).

Clay is an important component of drilling fluid. Researchers have carried out detailed and in-depth studies on the influence of clay content, aging temperature, $\mathrm{pH}$ value, salinity and other factors on its high-temperature rheological properties (Choo and Bai 2015; Vryzas et al. 2016; Magzoub et al. 2017). However, polymers, as another important component of drilling fluids, have been rarely studied for their high-temperature rheological properties. Especially for clay-free drilling fluids, the rheological properties are significantly different from that of the clay slurry (Bu et al. 2013; Huang et al. 2016a, b). If the rheological behavior of the clay slurry is applied to the polymeric fluid, it will produce erroneous results. Therefore, it is of great practical significance to carry out researches on the high-temperature rheological properties of polymer solutions.

Polymer fluids, in contrast to water, exhibit non-Newtonian properties, such as shear-thinning or shear-thickening 
behavior (Mnekbi et al. 2010; Ouaer and Gareche 2018; Cheraghian et al., 2015). Owing to its remarkable performance, such as controllable rheological properties, excellent shale inhibition capacity, environmentally friendly and etc., polymer systems find a wide range of applications in oil and gas industries (Tehrani et al. 2009; Stefano et al. 2013). Due to immense interest in this area, some of experimental observation and theoretical predictions have pointed to large number of variables, including the types of polymer, the concentrations of polymer, different electrolytes in solution and so on (Ghannam and Esmail 2002; Pancharoen 2009; Al-hashmi et al. 2013). With the increasing depth of well, the increasing temperature has an adverse impact on rheological behaviors. Mozaffari et al. (2015) reported that aging the diluted bitumen solution accounts for the reduction in the viscosity. The rheological properties of bitumen solutions are investigated in nanoscale, and the phenomenon can be interpreted as the incessant asphaltene aggregation and precipitation in high-temperature environments.

In addition, it is believed that polymer chains relax and extend in fresh water, resulting in high fluid viscosity. However, drilling fluids will be polluted by various types of saltbearing strata and high mineralized formation brine, and the salinity has a major impact on polymers. Gao (2016) performed the rheological measurements of high acyl gellan gum in different brine, showing that the viscosity of all polymer solutions decreased due to the curling of polymer chains after the salt added. Besides, it has been well supported in a number of studies that the absorption characteristics of polymer on clay particles surface play a crucial role in the stability of water-based drilling fluids. Cheraghian et al. (2015) focused on the role of clay nanoparticles on polyacrylamide polymer viscosity and concluded that nanoclay can improve viscosity of polymer solution.

Despite the fact that a number of studies reported the data on rheological behavior of polymer at different concentrations, temperatures and salinity, until now, the understanding of the high temperature (above $200{ }^{\circ} \mathrm{C}$ ) on rheological behavior of polymer solutions has not been studied systematically. In this paper, we performed high-temperature rheology analysis for polymer solutions in the presence of inorganic and organic salts, clay and antioxidant.

\section{Experimental section}

\section{Materials}

Sodium chloride $(\mathrm{NaCl})$, potassium chloride $(\mathrm{KCl})$, sodium formate $(\mathrm{HCOONa})$, potassium formate $(\mathrm{HCOOK})$ and calcium sulfate $\left(\mathrm{CaSO}_{4}\right)$ are analytical reagent and commercially available. Bentonite (NV-1) was purchased from Zhongfei Xiazijie Bentonite Co., Ltd. (Xinjiang, China); Sepiolite (SEP) was obtained from Xiangtan Yanyuan Sepiolite New Materials Co., Ltd. The synthetic polymers Driscal-D used in this study are bought from Chevron Phillips Chemical Co., Ltd. (America). The information regarding physical and chemical properties of clays and Driscal-D is provided in Table 1 and Table 2, respectively.

\section{Sample preparation}

Polymer solution was prepared by adding the desired amount of polymer powder to volume of $400 \mathrm{~mL}$ distilled water with stirring at 11,000 rpm for $20 \mathrm{~min}$. To ensure the full hydration of the polymer, the stirred polymer solution was kept at room temperature for $24 \mathrm{~h}$ to stand by.

Clay/polymer suspension was prepared by adding $16 \mathrm{~g}$ of clay into $400 \mathrm{~mL}$ of distilled water to get $4 \%$ of mass concentration and was mixed at $11000 \mathrm{r} / \mathrm{min}$ for $20 \mathrm{~min}$. Then, the required amount of polymer was mixed with clay slurry and stirred at $11000 \mathrm{rpm}$ for another $20 \mathrm{~min}$. Subsequently, the mixture of polymer and clay was kept at room temperature for $24 \mathrm{~h}$.
Table 1 Chemical and physical properties of clay particles

\begin{tabular}{lllllll}
\hline Clay type & SG $(/)$ & Size $(\mu \mathrm{m})$ & $\begin{array}{l}\text { Water } \\
\text { content } \\
(\%)\end{array}$ & $\begin{array}{l}\mathrm{CEC} \\
(\mathrm{meq} / 100 \mathrm{~g})\end{array}$ & Shape & Chemical formula \\
\hline Bentonite & 2.5 & $<74$ & 11.2 & 92.4 & Platelet & $\mathrm{Al}_{2} \mathrm{Mg}_{3} \mathrm{Si}_{4} \mathrm{O}_{10}(\mathrm{OH})_{2} \bullet \mathrm{nH}_{2} \mathrm{O}$ \\
Sepiolite & 2.3 & $<74$ & 9.8 & 30 & Rod-like & $\mathrm{Si}_{12} \mathrm{Mg}_{8} \mathrm{O}_{10}(\mathrm{OH})_{4} \bullet 8 \mathrm{H}_{2} \mathrm{O}$ \\
Attapulgite & 2.2 & $<74$ & 12.4 & 18 & Rod-like & $\mathrm{Si}_{8} \mathrm{Mg}_{5} \mathrm{O}_{20}(\mathrm{OH})_{2}\left(\mathrm{OH}_{2}\right)_{4} \bullet 4 \mathrm{H}_{2} \mathrm{O}$ \\
\hline
\end{tabular}

Table 2 Information of Driscal-D

\begin{tabular}{lllllll}
\hline Chemical name & Form & Physical state & Color & Size $(\mu \mathrm{m})$ & Relative density & Water solubility \\
\hline 2-Acrylamido-2methylpropane sulfonic acid, sodium salt & Power & Solid & White & $105-125$ & 1.44 & Complete soluble \\
\hline
\end{tabular}


Before HTHP rheology test, all the fully hydrated fluid samples were placed in a high speed mixer and stirred for 5 min to ensure that they suffered the same shear history.

\section{Rheological measurements}

Rheological properties of prepared solution were measured with Fann 50 SL HTHP Rheometer, Fann Instrument Company (America). Firstly, the sample of about $42 \mathrm{~mL}$ is poured into a sample cup. Secondly, open the automated testing software, set the required test temperature and speed, and then adjust the pressure to 1000 psi via the nitrogen cylinder to ensure that the sample does not boil during the testing process. Finally, the test data are exported and processed by data analysis software. In this work, the temperature collection points are $40{ }^{\circ} \mathrm{C}, 70{ }^{\circ} \mathrm{C}, 100{ }^{\circ} \mathrm{C}, 130{ }^{\circ} \mathrm{C}$, $160{ }^{\circ} \mathrm{C}, 190^{\circ} \mathrm{C}$ and $220^{\circ} \mathrm{C}$, and the shear rates are $5.11 \mathrm{~s}^{-1}$, $10.22 \mathrm{~s}^{-1}, 85.15 \mathrm{~s}^{-1}, 170.3 \mathrm{~s}^{-1}, 255.5 \mathrm{~s}^{-1}, 511 \mathrm{~s}^{-1}$. The test interval time at each shear rate was $1 \mathrm{~min}$ at each temperature, and all the rheological data were recorded at time intervals of $2 \mathrm{~s}$ at each shear rate. The temperature was controlled by using an oil bath connected to the bottom plate.

\section{Results and discussion}

\section{Effect of polymer addition on rheological properties}

The rheological characteristics of polymer solutions of Driscal-D with concentration of $0.75 \%(\mathrm{w} / \mathrm{v}), 1.25 \%(\mathrm{w} / \mathrm{v})$ and $2 \%(\mathrm{w} / \mathrm{v})$ were obtained by HTHP rheology test, and the rheological curves were fitted as shown in Fig. 1. The shear stress versus shear rate curves are in accord with the power law model with the correlation coefficient greater than

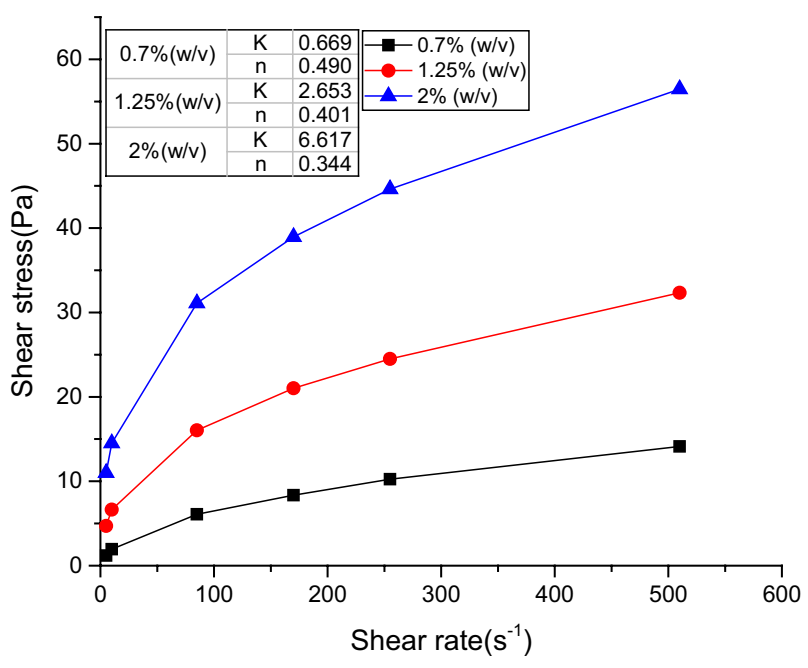

Fig. 1 Rheology model fitting of polymer solutions $\left(40^{\circ} \mathrm{C}\right)$
0.994. As the polymer addition increases from $0.75 \%(\mathrm{w} / \mathrm{v})$ to $1.25 \%(\mathrm{w} / \mathrm{v})$ and $2 \%(\mathrm{w} / \mathrm{v})$, the $K$ value increases from $0.669 \mathrm{~Pa} \mathrm{~s}^{\mathrm{n}}$ to $2.653 \mathrm{~Pa} \mathrm{~s}^{\mathrm{n}}$ and $6.617 \mathrm{~Pa} \mathrm{~s}{ }^{\mathrm{n}}$, while the $\mathrm{n}$ value decreases from 0.49 to 0.401 and 0.344 . That is, the viscosity of polymer solution increases gradually as the amount of polymer increases. Obviously, the pseudoplastic fluid property of polymer solution becomes more noticeable.

As shown in Fig. 2, the effect of polymer addition on the viscosity at different shear rates was further studied. At the low shear rate of $5.11 \mathrm{~s}^{-1}$, the viscosity increases from 239.6 to $943.1 \mathrm{mPa}$ s (increased by 2.9 times) and $2201.1 \mathrm{mPa} \mathrm{s}$ (8.2 times). However, the viscosity at the high shear rate of $511 \mathrm{~s}^{-1}$ increases from 27.7 to $63.4 \mathrm{mPa} \mathrm{s}$ (1.3 times) and $110.7 \mathrm{mPa}$ s (2.9 times). The effect of polymer concentration at the low shear rates is more pronounced than at the high shear rates, which is consistent with the research of Ghannam and Esmail (2002). The main reason is that higher concentration increases the number of molecular chains per unit volume, thereby shortening the distance between molecules and enhancing the strength of intermolecular entanglement to form networks (Zhang 2011). It is apparent that the viscosity fluctuation varies at different shear rates, mainly because in the low shear rate range, the entanglement network between the chains is relatively stable and is difficult to be destroyed by shear forces. While at high shear rates, the coiled and convoluted molecular chains would be stretched and the entangled chains structure easily be broken (Chen et al. 2004).

To investigate the impact of temperature on the viscosity of polymer solution, the variation in viscosity with temperature at a shear rate of $511 \mathrm{~s}^{-1}$ is plotted in Fig. 3 . As illustrated in Fig. 3, the viscosity decreases linearly as temperature increases and then falls sharply at temperature

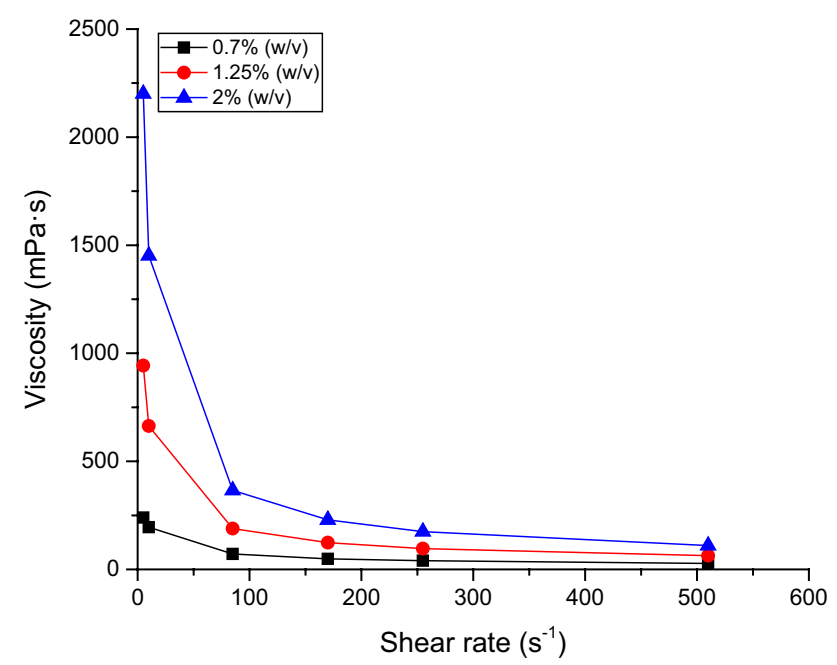

Fig. 2 Influence of polymer additions on viscosity at different shear rates 


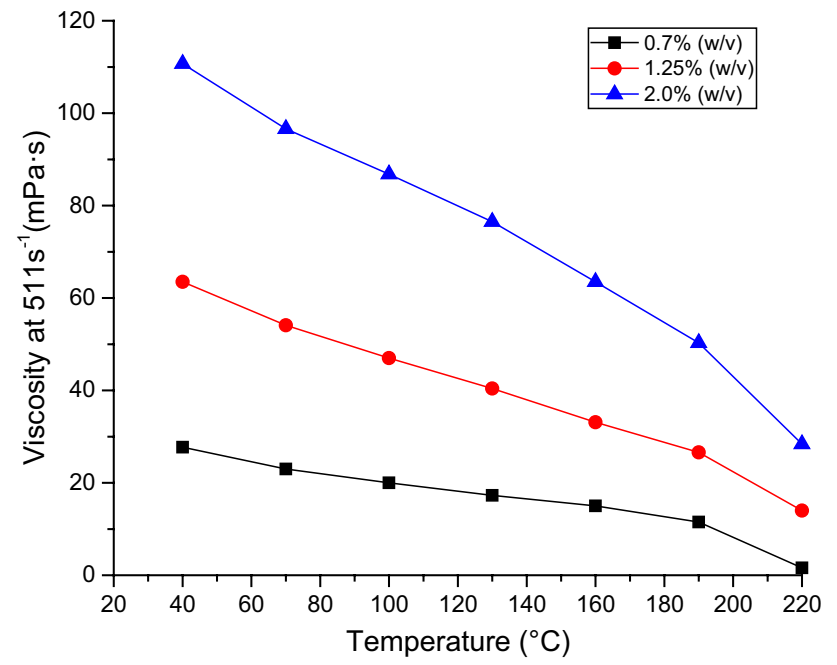

Fig. 3 Viscosity-temperature curve of polymer solution

exceeding $190{ }^{\circ} \mathrm{C}$. At the temperature of $220^{\circ} \mathrm{C}$, the viscosity with concentration of $0.7 \%(\mathrm{w} / \mathrm{v}), 1.25 \%(\mathrm{w} / \mathrm{v})$ and $2 \%$ $(\mathrm{w} / \mathrm{v})$ decreases to $1.6 \mathrm{mPa} \mathrm{s}, 16 \mathrm{mPa}$ s and $28.4 \mathrm{mPa} \mathrm{s}$, respectively. Compared with the initial viscosity value at $40{ }^{\circ} \mathrm{C}$, the viscosity reduction rates reach up to $94 \%, 78 \%$ and $74 \%$, respectively. This phenomenon can be described by Arrhenius equation (Xie et al. 2018). Increasing temperature tends to enhance the activity of molecules and meanwhile reduces the interaction between the molecules by weakening the hydrogen bonds, which leads to the decrease in viscosity of the whole fluid system.

When compared with Fig. 1, it can be concluded that the high temperature causes a noticeable decrease in the viscosity of the polymer fluids (as shown in Fig. 4). For the 0.7\% $(\mathrm{w} / \mathrm{v}), 1.25 \%(\mathrm{w} / \mathrm{v})$ and $2 \%(\mathrm{w} / \mathrm{v})$ concentration of Driscal-D

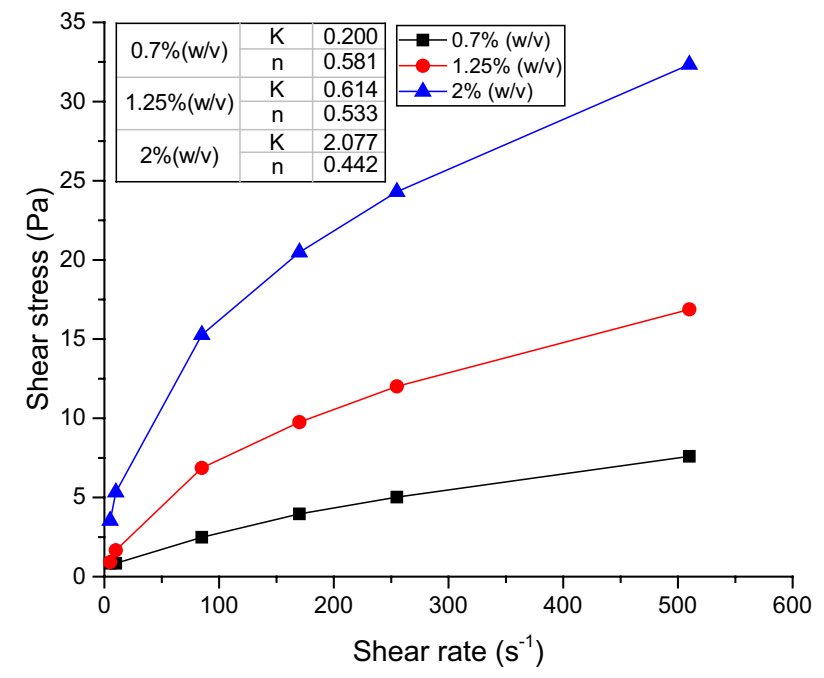

Fig. 4 Rheology model fitting of polymer solutions $\left(160^{\circ} \mathrm{C}\right)$ solutions, the $K$ values reduce to $0.2 \mathrm{~Pa} \bullet \mathrm{s}^{\mathrm{n}}, 0.614 \mathrm{~Pa} \bullet \mathrm{s}^{\mathrm{n}}$ and $2.077 \mathrm{~Pa} \bullet \mathrm{s}^{\mathrm{n}}$, respectively, and the $\mathrm{n}$ values increase to 0.581 , 0.533 and 0.442 , respectively. This indicates that there is an increasing tendency to evolve the polymeric system from a pseudoplastic fluid to a Newtonian fluid.

\section{Effect of electrolyte}

\section{Different types of salt on polymer rheological behavior}

The rheological properties of polymer solution in different electrolytes were investigated. The amounts added in the polymer solution were as follows: $5 \%(\mathrm{w} / \mathrm{v}) \mathrm{NaCl}, 5 \%(\mathrm{w} / \mathrm{v})$ $\mathrm{NaCOOH}, 5 \%(\mathrm{w} / \mathrm{v}) \mathrm{KCl}, 5 \%(\mathrm{w} / \mathrm{v}) \mathrm{KCOOH}$ and $0.5 \%(\mathrm{w} / \mathrm{v})$ $\mathrm{CaSO}_{4}$.

As shown in Fig. 5, it is clear that the addition of electrolyte gives an obvious reduction in viscosity of polymer solutions, which is explained by the shielding effect of the charge redistribution. Sodium and calcium cations, which are opposite to the surface charge of the polymer molecular chain, are ionized from soluble salt and concentrated near the hydration group of polymer molecules, and the thickness of the double electric layer decreases, resulting in the decrease in the $\xi$ potential. When the diffusion layer is compressed to a thickness close to zero, the negative charge on the surface of the polymer molecular chain is nearly completely neutralized, which leads to the reduction in its hydrodynamic size, the electrical shielding of its ionic groups, the weakening of the repulsive force within polymer molecular chain, and then resulting in curled-up polymer molecules (Son et al. 1987; Hou et al. 2003; Samanta et al. 2010).

Besides, it is worth noticing that formate is capable of retaining the viscosity, i.e., the polymer solution with added sodium formate shows the lowest viscosity reduction rate,

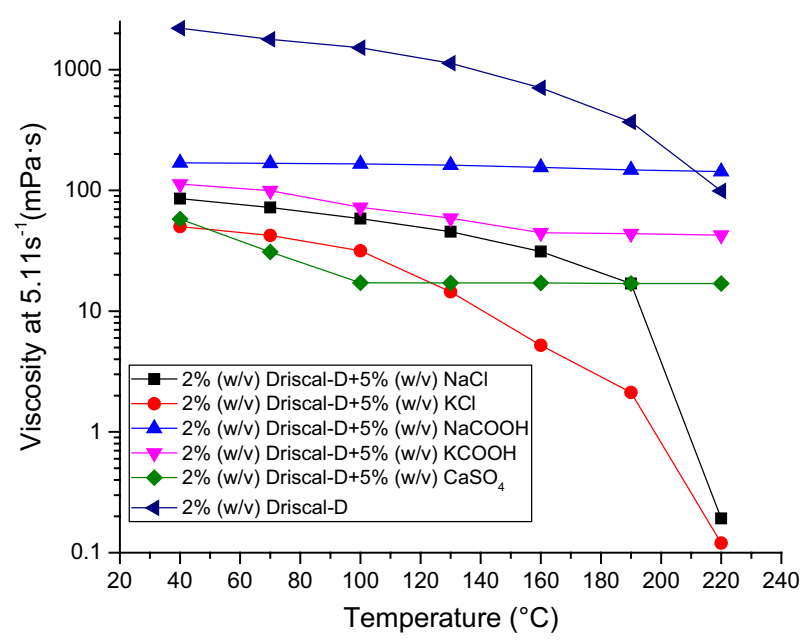

Fig. 5 Viscosity of salt-containing polymer solutions varies with temperature 
and potassium formate is in the second place (Fig. 6). The viscosity of the formate-containing Driscal-D solution is greater than pure Driscal-D fluids up to $220^{\circ} \mathrm{C}$. Apparently, this can be explained as follows: Formate changes the structure of surrounding water molecules in the fluid, which affects the structure of dissolved high molecular weight polymers. The polymer structure becomes more ordered, strong and stable at elevated temperatures. As a result, adding formate can improve the flow behavior of the polymer fluids at high temperatures (Howard et al. 2015; Bungert et al. 2000; Akpan et al. 2019).

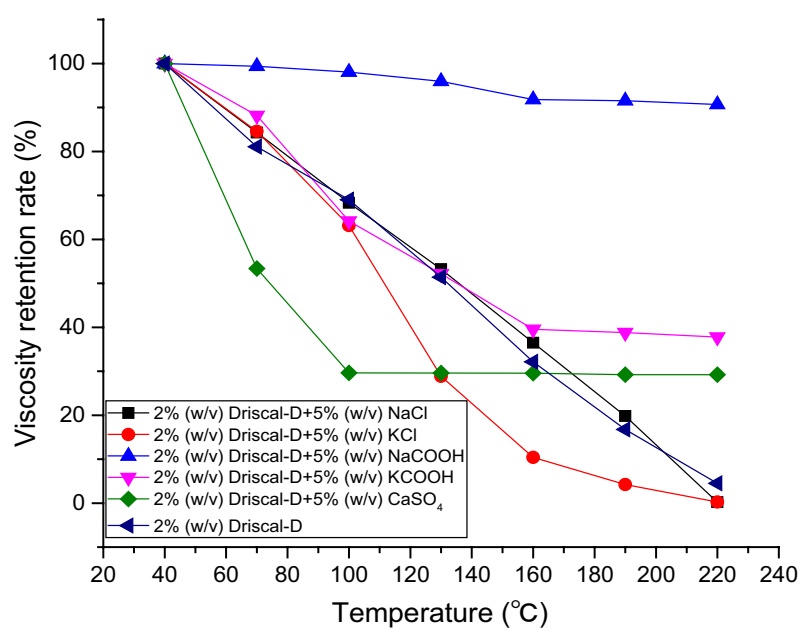

Fig. 6 Viscosity retention rate of salt-containing polymer solutions varies with temperature. Note: The percentage of viscosity at current temperature to that at $40{ }^{\circ} \mathrm{C}$ is taken as the retention rate of viscosity
Furthermore, calcium sulfate exhibits stronger charge shielding effect, and the viscosity even ceases to change when its concentration exceeds $0.5 \%$ at $100{ }^{\circ} \mathrm{C}$. Calcium sulfate, a salt with chemical formula $\mathrm{CaSO}_{4}$, poses some serious hazards. $\mathrm{Ca}^{2+}$ has a greater influence on the size of polymer molecular coils, mainly due to the higher valence number of $\mathrm{Ca}^{2+}$ than of $\mathrm{Na}^{+}$at the same concentration, and the ability to neutralize the negative charge on the polymer surface layer is stronger, a large reduction in the thickness of the diffusion layer and a sharp curl of the polymer molecular chain, causing precipitation of the polymer from the aqueous phase of the mud system (Lu et al. 2007; Sepehri et al. 2018).

\section{Thermal protection effect of formate}

To further investigate the high-temperature protection effect of formate on the polymer, the rheological recovery rates of polymer solution with formate and inorganic salt during heating and cooling processes have been compared.

As illustrated in Fig. 7, during the heating process, the viscosity of the solution containing salt decreases greatly after being subjected to high temperature varying from $40{ }^{\circ} \mathrm{C}$ to $220^{\circ} \mathrm{C}$. Among them, the influence of $\mathrm{NaCl}$ on the viscosity of Driscal-D solution is more obvious. When the temperature rises up to $220^{\circ} \mathrm{C}$, the viscosity is basically lost. In contrast, in the formate environment, Driscal-D solution can maintain the viscosity value around $10 \mathrm{mPa}$ s. During the cooling process, the viscosity of the polymer shows little sign of recovering in $\mathrm{NaCl}$ environment, indicating that the structure of Driscal-D was almost completely destroyed in the inorganic salt environment. However, as the temperature

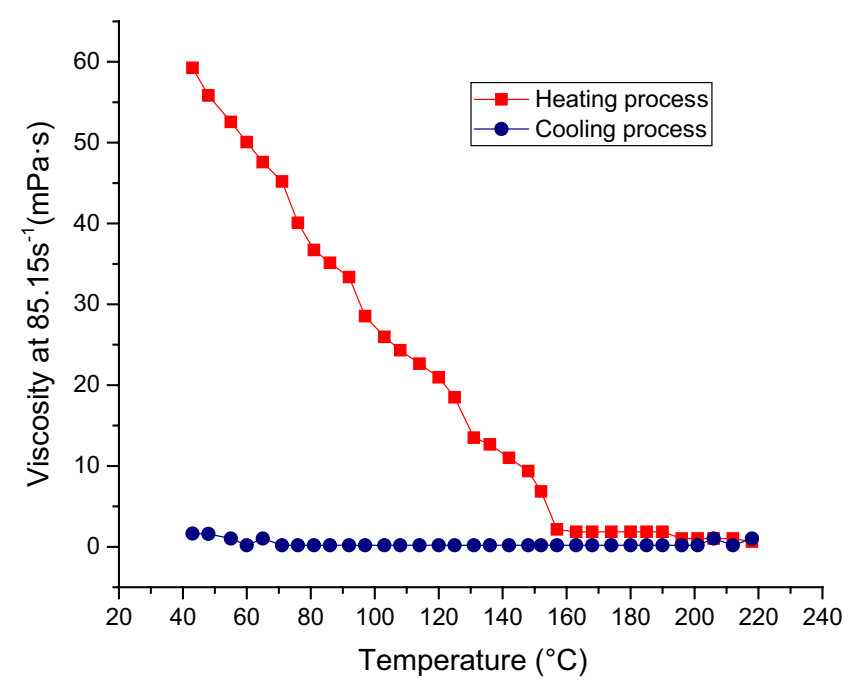

(a) $2 \%$ Driscal- $\mathrm{D}+5 \% \mathrm{NaCl}$

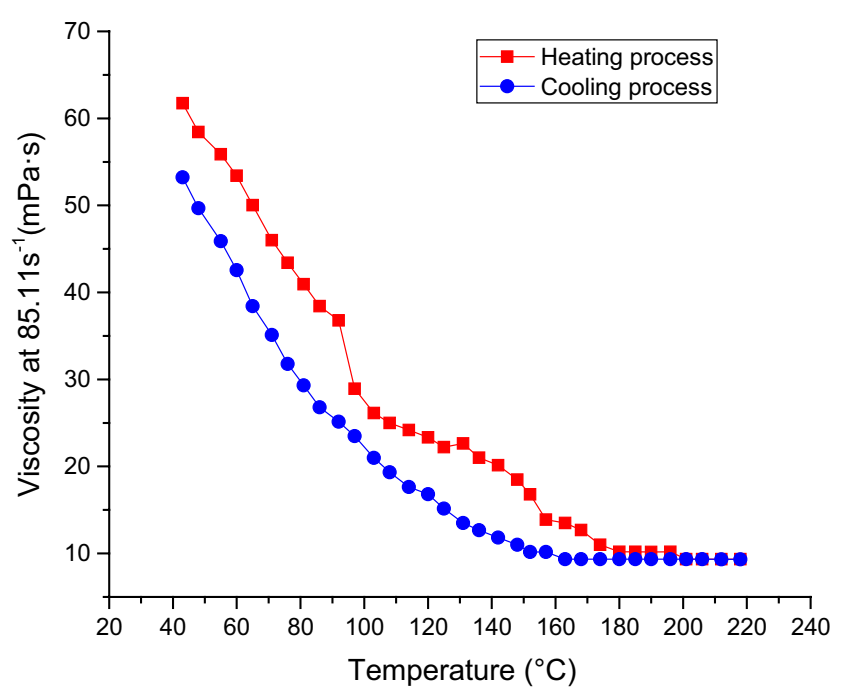

(b) $2 \%$ Driscal-D $+5 \% \mathrm{NaCOOH}$

Fig. 7 Viscosity recovery rate of Driscal-D with $\mathrm{NaCl}$ or $\mathrm{NaCOOH}$ after heating-cooling process (at shear rate of $85.15 \mathrm{~s}^{-1}$ ) 
decreases, the viscosity recovery rate of the Driscal-D solution with sodium formate can be as high as about $50 \%$. Based on the above analysis, formate has a certain hightemperature protection effect on the polymer.

\section{Effect of clay}

Bentonite is mainly composed of montmorillonite, the swelling potential and colloidal behavior (particle-particle interaction) of which is controlled by the layer composition, the layer charge and the nature of exchangeable interlayer cation (Christidis et al. 2006). The layered structure of bentonite has the capacity to adsorb water molecules in between layers and resulting in the increase in swelling by increasing the c-axis dimension of clays (Aftab et al. 2016). Both attapulgite and sepiolite are hydrous magnesium silicates with a fibrous or acicular morphology, and they separate to individual laths when mixed vigorously with water. The typical SEM images of bentonite, sepiolite and attapulgite were shown in literatures of Huang et al. (2016b), Grust et al. (2015) and Lee (1984). All of the clays mentioned above can be used to formulate drilling fluid for rheology control. Bentonite dispersion is prone to be thickening at elevated temperature, which can be attributed to the formation of clusters and enhanced face-to-face interactions (Ahmad et al. 2018). As for attapulgite and sepiolite, the viscosity is quite stable at high temperatures. However, the disadvantage is that they provide no filtration control because of their rod-like shape.

The rheological properties of clay/polymer dispersion (Driscal-D solution, Driscal-D with NV-1, Driscal-D with SEP and Driscal-D with ATTP dispersion) were investigated at temperature range of $40-220^{\circ} \mathrm{C}$. The flow curves of these dispersions are presented in Fig. 8. All samples exhibit non-Newtonian behavior over the entire temperature range. Also, the Driscal-D/clay dispersion shows obviously higher shear stress values at the entire shear rate range compared to Driscal-D solution. The incorporation of the clay in DriscalD solution enhances the rheological properties, which could be explained by the adsorption of polymer chains on bentonite platelets (Safi et al. 2016). What is more, the shear stress values of NV-1 and SEP dispersions are practically close at different temperatures, and simultaneously, these values are higher than the ATTP dispersion. Thus, the order of shear stress of all the dispersion is presented as: NV-1/DD > SEP/ DD $>$ ATTP/DD.

It is well documented in the literature that most of the water-bentonite dispersions are fitted very well with Herschel-Bulkley model (Kelessidis et al. 2006), and the rheological parameters estimation is performed according to the equation:

$\tau=\tau_{0}+k \dot{\gamma}^{\mathrm{n}}$ where $\tau$ is the shear stress, $\tau_{0}$ is the yield stress, $\dot{\gamma}$ is the shear rate, $\mathrm{k}$ is the consistency coefficient and $\mathrm{n}$ is the flow behavior index. Herschel-Bulkley rheological parameters were determined using nonlinear regression analysis by fitting rheometer data in the Origin with Fitting function. Equation (1) reduces to a Newtonian fluid when $\mathrm{n}=1$ and $\tau_{0}=0$ (Onuh et al. 2019). The parameters and the statistical indicator coefficient of determination $R^{2}$ are listed in Table 3 .

Table 3 shows that Herschel-Bulkley model gives high value ( $>0.99$ ) of $R^{2}$ over the whole clay/polymer suspension, indicating that Herschel-Bulkley model fits well with the experimental data. It is clear that as temperature increases from 40 to $220^{\circ} \mathrm{C}$, the value of the yield point $\left(\tau_{0}\right)$ and the flow consistency index $(k)$ decreases, and flow behavior index $(n)$ increases. Amira et al. (2015) concluded that the increasing value of $K$ indicated the hole-cleaning capacity of drilling fluid would increase owing to the strengthening of annular viscosity. When the values of $\tau_{0}$ decrease, the network structure between the polymer chains and clay particles becomes weak and destroyed upon heating.

\section{Effect of antioxidant}

According to previous researches, the presence of oxygen could lead to the oxidative degradation of the polymer, which causes the viscosity to decrease with aging. In order to investigate the effect of antioxidant on the rheological behavior of the polymer solution at elevated temperatures, the viscosity measurement shown in Fig. 9 was taken at $240{ }^{\circ} \mathrm{C}$ with or without an antioxidant.

It is clearly observed from Fig. 8 that the effect of dissolved oxygen on the viscosity of Driscal-D solution is not obvious at low temperatures, which means that the viscosity could be stable at some extent. However, as temperature increases, in the presence of oxygen, the viscosity decreases with shear rate rather quickly. The viscosity of Driscal-D solution with $\mathrm{Na}_{2} \mathrm{SO}_{3}$ is much higher than that without antioxidant over the whole shear rates, which can be interpreted as follows: The acid radicals ionized by the sodium sulfite are reductants capable of scavenging oxygen from the system, providing anaerobic conditions (Hashmet et al. 2013). Especially for the low shear rates $\left(<50 \mathrm{~s}^{-1}\right)$, the Driscal-D solution still exhibits rather high viscosity at elevated temperature. This is mainly because the oxygen forms free radicals, which might have destroyed the polymer backbone or chain, and the process is enhanced at higher temperatures. As a consequence, the reduction in molecular weight of the polymer reduces the viscosity (Levitt and Pope 2008; Vermolen et al. 2011). 


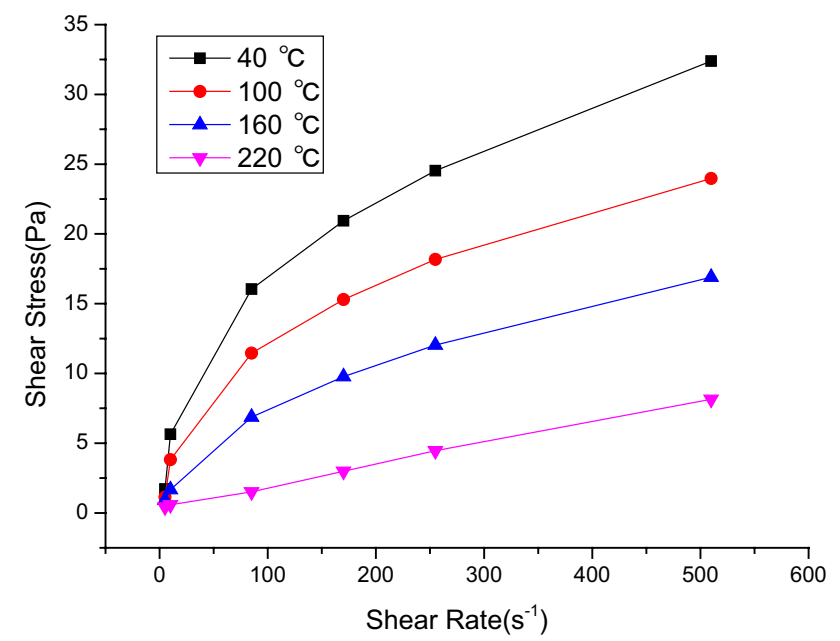

(a) Driscal-D

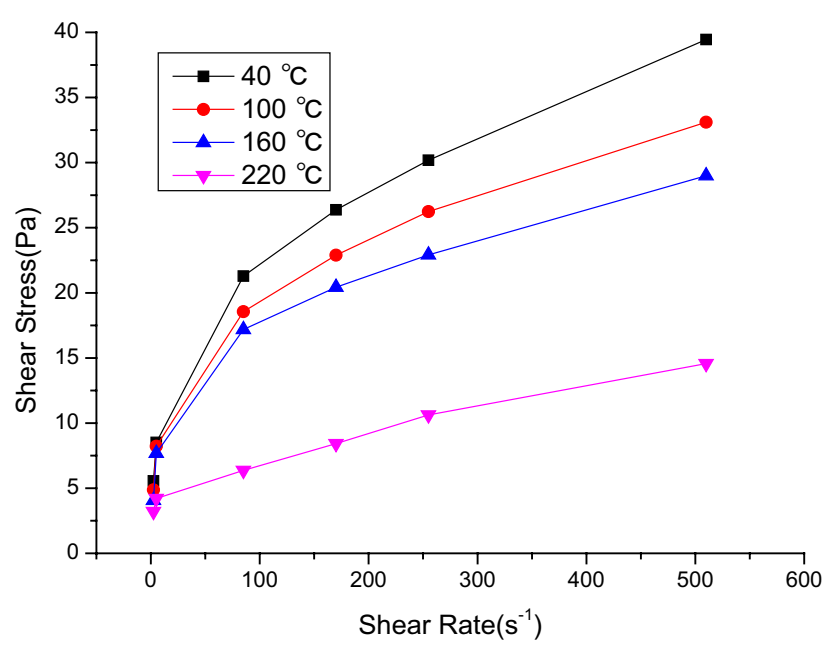

(c) SEP+ Driscal-D

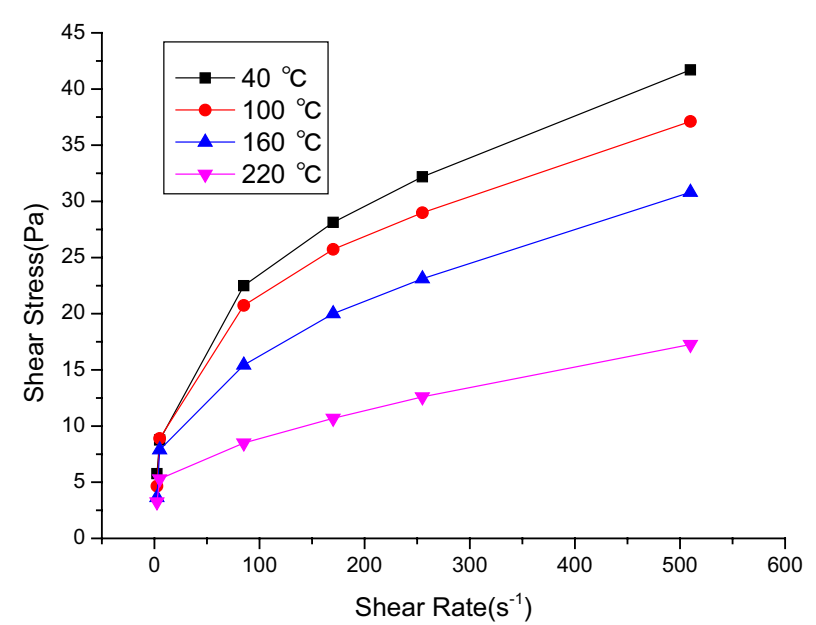

(b) NV-1+ Driscal-D

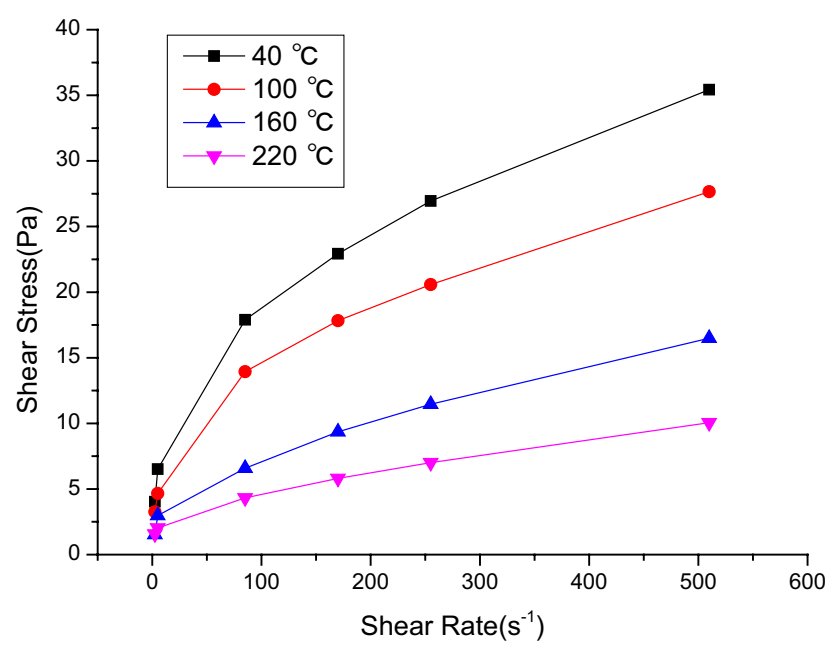

(d) ATTP+ Driscal-D

Fig. 8 Flow curves of Driscal-D with or without clay at different temperatures

Table 3 Fitting parameters of Herschel-Bulkley model

\begin{tabular}{lrrlll}
\hline Sample & $\begin{array}{l}\text { Temperature } \\
\left({ }^{\circ} \mathrm{C}\right)\end{array}$ & \multicolumn{1}{l}{$\tau_{0}$} & \multicolumn{1}{l}{$K$} & \multicolumn{1}{l}{$R^{2}$} \\
\hline 4\%NV-1+1.25\%Driscal-D & 40 & 11.69 & 4.98915 & 0.34148 & 0.9982 \\
& 100 & 10.93 & 4.20239 & 0.39543 & 0.9927 \\
& 160 & 8.41 & 2.12987 & 0.41649 & 0.9922 \\
& 220 & 5.47 & 0.42045 & 0.55998 & 0.9902 \\
$4 \%$ SEP-1+1.25\%Driscal-D & 40 & 11.11 & 4.32497 & 0.25236 & 0.9972 \\
& 100 & 10.12 & 4.40498 & 0.31198 & 0.9949 \\
& 160 & 9.24 & 2.45721 & 0.35529 & 0.9907 \\
& 220 & 4.18 & 0.14934 & 0.69487 & 0.9905 \\
\hline
\end{tabular}




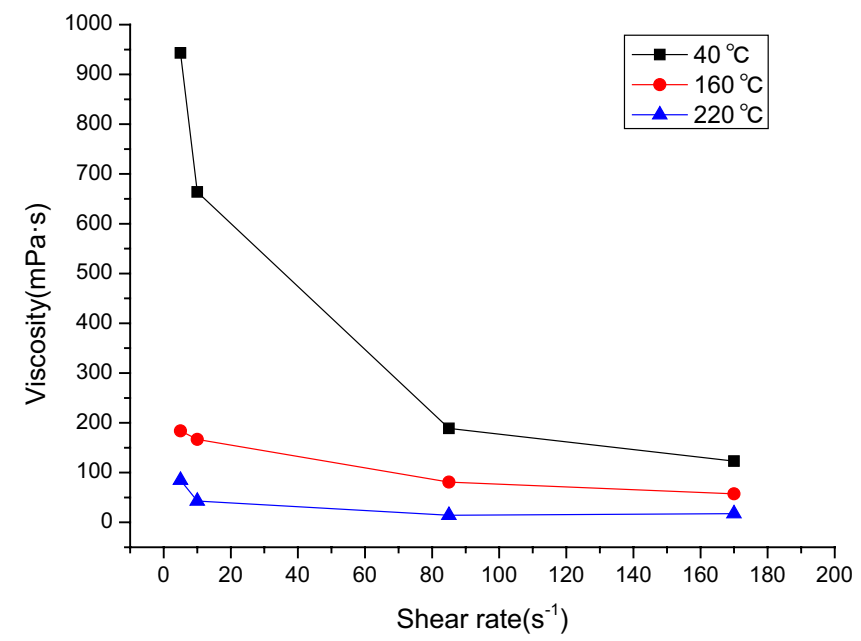

(a) $1.25 \%(\mathrm{w} / \mathrm{v})$ Driscal-D

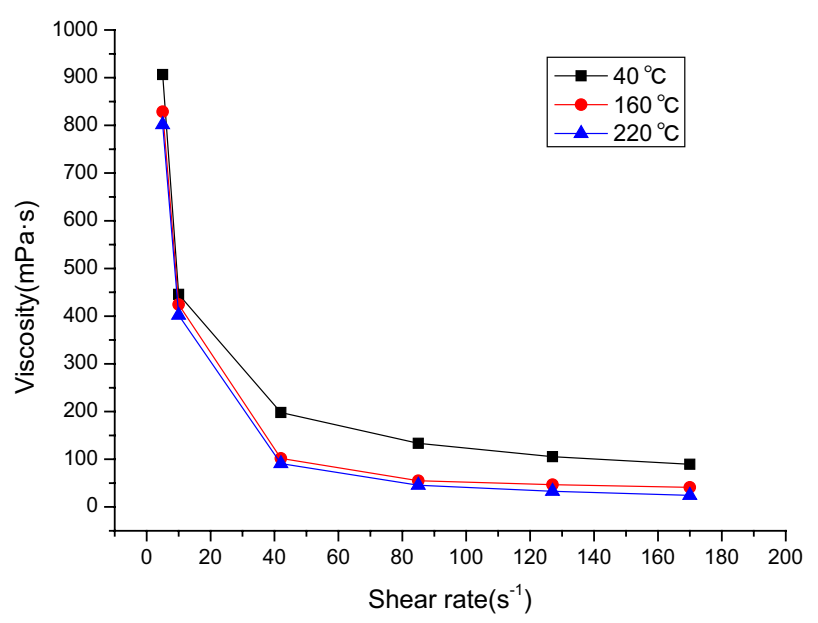

(b) $1.25 \%(\mathrm{w} / \mathrm{v})$ Driscal-D $+0.1 \%(\mathrm{w} / \mathrm{v}) \mathrm{Na}_{2} \mathrm{SO}_{3}$

Fig. 9 Effect of antioxidant on rheological behavior of Driscal-D solution at HTHP condition

\section{Conclusion}

In this experimental study, the affect factors on rheological characteristic of polymer fluid at HTHP conditions have been investigated. In the HTHP rheological experiments of six polymers, Driscal-D exhibited the best high-temperature resistance due to its highest viscosity retention rate. In addition, the effect of different electrolytes on rheological behavior of Driscal-D solution was significantly distinct. During heating-cooling process, in the presence of $\mathrm{NaCl}$ and $\mathrm{KCl}$ environment, the polymer viscosity was basically lost when the temperature increased to $220^{\circ} \mathrm{C}$, while the viscosity recovery rate of the Driscal-D solution with sodium formate or potassium formate could be as high as about 50\% during cooling process. This suggests that formate would be beneficial to the thermal stability of polymer fluid at HTHP conditions. As for clay, the rheological properties of Driscal-D with bentonite/sepiolite dispersion at HTHP showed the incorporation of the clay in Driscal-D solution enhanced the rheological properties, which was benefit for carrying cuttings. And the dispersion was best described by Herschel-Bulkley model. Finally, with adding antioxidant, most of the change in the shear viscosity with temperature occurs at low shear rates $\left(<50 \mathrm{~s}^{-1}\right)$, and the Driscal-D solution with antioxidant could remain rather high viscosity value at elevated temperature.

Acknowledgements This paper has been supported by the China Geological Survey Projects (Project No. DD20160209) and SinoProbe-05 (Project No. 201011082).
Open Access This article is distributed under the terms of the Creative Commons Attribution 4.0 International License (http://creativeco mmons.org/licenses/by/4.0/), which permits unrestricted use, distribution, and reproduction in any medium, provided you give appropriate credit to the original author(s) and the source, provide a link to the Creative Commons license, and indicate if changes were made.

\section{References}

Abdelgawad KZ, Elzenary M, Elkatatny S, Mahmoud M, Abdulraheem A, Patil S (2019) New approach to evaluate the equivalent circulating density (ECD) using artificial intelligence techniques. J Pet Explor Prod Technol 9(2):1569-1578

Aftab A, Ismail A, Ibupoto Z (2016) Enhancing the rheological properties and shale inhibition behavior of water-based mud using nanosilica, multi-walled carbon nanotube and graphene nanoplatelet. Egypt J Pet 26(2):291-299

Ahmad HM, Kamal MS, Al-harthi MA (2018) Effect of thermal aging and electrolyte on bentonite dispersions: rheology and morphological properties. J Mol Liq 269:278-286

Akpan EU, Enyi GC, Nasr G, Yahaya AA, Ahmadu AA, Saidu B (2019) Water-based drilling fluids for high-temperature applications and water-sensitive and dispersible shale formations. J Pet Sci Eng 130:1028-1038

Al-Azani K, Elkatatny S, Ali A, Ramadan E, Abdulraheem A (2019) Cutting concentration prediction in horizontal and deviated wells using artificial intelligence techniques. J Petrol Explor Prod Technol 9(2):1-11

Al-Hashmi AR, Luckham PF, Heng JYY, Al-Maamari RS, Zaitoun A, Al-Sharji HH, Al-Wehaibi TK (2013) Adsorption of high molecular-weight EOR polymers on glass surfaces using AFM and QCM-D. Energy Fuels 27(5):2437-2444

Amira Z, Jan BM, Khalil M, Abdul W, Ahmad K, Hassan Z (2015) Rheological behavior and temperature dependency study of 
Saraline-based super lightweight completion fluid. J Pet Sci Eng 130:106-113

Bland RG, Mullen GA, Gonzalez YN, Harvey FE, Pless ML (2006) HPHT drilling fluid challenges. In: IADC/SPE Asia Pacific drilling technology conference and exhibition

Bu H, Sun JS, Wang CB, Bu P (2013) Rheological properties of polymer-gel drilling fluids at high temperature and pressure. Chem Technol Fuels Oils 48(6):449-458

Bungert D, Maikranz S, Sundermann R, Downs J, Benton W, Dick MA (2000) The evolution and application of formate brine in high-temperature high-pressure operations. In: IADC/SPE drilling conference

Chen YZ, Zhang Z, Chen MH, Zhang XH, Tian QS, Xing LM, Ma T (2004) Analysis of the main factors affecting the viscosity of the solution of polymer. Liaoning Chem Ind 33(5):258-260

Cheraghian G, Nezhad SSK, Kamari M, Hemmati M, Masihi M, Bazgir S (2015) Effect of nanoclay on improved rheology properties of polyacrylamide solutions used in enhanced oil recovery. J Pet Explor Prod Technol 5(2):189-196

Choo KY, Bai K (2015) Effects of bentonite concentration and solution $\mathrm{pH}$ on the rheological properties and long-term stabilities of bentonite suspensions. Appl Clay Sci 108:182-190

Christidis GE, Blum AE, Eberl DD (2006) Influence of layer charge and charge distribution of smectites on the flow behavior and swelling of bentonites. Appl Clay Sci 34:125-138

Fisk JV, Jamison DE (1989) Physical properties of drilling fluids at high temperatures and pressures. SPE Drill Eng 4(4):341-346

Gao CH (2016) Unique rheology of high acyl gellan gum and its potential applications in enhancement of petroleum production. J Pet Explor Prod Technol 6(4):743-747

Ghannam M, Esmail N (2002) Flow behavior of enhanced oil recovery alcoflood polymers. J Appl Polym Sci 85(4):2896-2904

Grust A, Osgouei AE, Ozyurtkan MH, Serpen U (2015) Sepiolite based muds as an alternate drilling fluid for hot environments. In: Proceedings world geothermal congress

Hashmet MR, Onur M, Tan IM (2013) Empirical correlations for viscosity of polyacrylamide solutions with the effects of temperature and shear rate: II. J Dispers Sci Technol 35(12):1685-1690

Hou JR, Liu ZC, Zhang SF, Yue XA, Yang JZ (2003) Effect of alkali on molecular configuration of polymer and its rheological behavior. Acta Phys Chim Sim 19(3):256-259

Howard S, Kaminski L, Downs J (2015) Xanthan stability in formate brine-formulating non-damaging fluids for high-temperature applications. In: SPE European formation damage conference and exhibition

Huang WA, Xie BQ, Qiu ZS, Jiang L (2016a) Bentonite-free waterbased drilling fluid with high-temperature tolerance for protecting deep reservoirs. Chem Technol Fuels Oils 51(6):652-662

Huang WA, Leong YK, Chen T, Au PI, Liu XH (2016b) Surface chemistry and rheological properties of API bentonite drilling fluid: $\mathrm{pH}$ effect, yield stress, zeta potential and ageing behaviour. J Pet Sci Eng 146:561-569

Kelessidis V, Maglione R, Tsamantaki C, Aspirtakis Y (2006) Optimal determination of rheological parameters for Herschel-Bulkley drilling fluids and impact on pressure drop, velocity profiles and penetration rates during drilling. J Pet Sci Eng 53(3):203-224

Lee LJ (1984) Nature of the changes in clay minerals of the high temperature drilling fluids. Ph.D Dissertation at Texas Tech University

Levitt D, Pope GA (2008) Selection and Screening of Polymers for Enhanced-Oil Recovery. In: SPE symposium on improved oil recovery
Lu XG, Wang W, Sun G (2007) Effect of electrolyte on flow characteristic of polymer solution and its acting mechanism. Pet Geo Oil Develop Daqing 26(1):104-108

Magzoub MI, Nasser MS, Hussein IA, Benamor A, Onaizi SA, Sultan AS, Mahmoud MA (2017) Effects of sodium carbonate addition, heat and agitation on swelling and rheological behavior of $\mathrm{Ca}$ bentonite colloidal dispersions. Appl Clay Sci 147:176-183

Mnekbi C, Vincent M, Agassant JF (2010) Polymer rheology at high shear rate for microinjection moulding. Int $J$ Mater Form 3:539-542

Mozaffari S, Tchoukov P, Atias J, Czarnecki J, Nazemifard N (2015) Effect of asphaltene aggregation on rheological properties of diluted Athabasca bitumen. Energy Fuels 29(9):5595-5599

Onuh CY, Dosunmu A, Anawe A, Okoro EE, Lgwilo KC, Ehinmowo AB (2019) The rheological behavior of a pseudo-oil-based mud formulated with Hura crepitans plant oil as base fluid. J Petrol Explor Prod Technol 9(2):1-19

Ouaer H, Gareche M (2018) The rheological behaviour of a watersoluble polymer (HEC) used in drilling fluids. J Braz Soc Mech Sci Eng 40:380

Pancharoen M (2009) Physical properties of associative polymer solutions. MS Thesis, University Of Stanford

Safi B, Zarouri S, Chabane-Chaouache R, Saidi M, Benmounah A (2016) Physico-chemical and rheological characterization of water-based mud in the presence of 7polymers. J Pet Explor Prod Technol 6(2):185-190

Samanta A, Bera A, Ojha K, Mandal A (2010) Effects of alkali, salts, and surfactant on rheological behavior of partially hydrolyzed polyacrylamide solutions. J Chem Eng 55(10):4315-4322

Sepehri S, Soleyman R, Varamesh A, Valizadeh M, Nasiri A (2018) Effect of synthetic water-soluble polymers on the properties of the heavy water-based drilling fluid at high pressure-high temperature (HTHP) conditions. J Pet Sci Eng 166:850-856

Son AJ, Ballard TM, Loftin E (1987) Temperature-stable polymeric fluid-loss reducer tolerant to high electrolyte contamination. In: SPE annual technical conference and exhibition

Stefano GD, Stamatakis E, Young S (2013) Meeting the ultrahightemperature/ultrahigh-pressure fluid challenge. SPE Drill Complet 28(1):86-92

Tehrani A, Gerrard D, Young S, Fernandez J (2009) Environmentally friendly water based fluid for HT/HP drilling, In: SPE International symposium on oilfield chemistry

Vermolen ECM, Van Haasterecht, MJT, Masalmeh SK, Faber MJ, Boersma DM, Gruenenfelder MA (2011) Pushing the envelope for polymer flooding towards high-temperature and high-salinity reservoirs with polyacrylamide based ter-polymers. In: SPE middle east oil and gas show and conference

Vryzas Z, Kelessidis VC, Nalbantian L, Zaspalis V, Gerogiorgis DI, Wukulikasasimu Y (2016) Effect of temperature on the rheological properties of neat aqueous Wyoming sodium bentonite dispersions. Appl Clay Sci 136:26-36

Xie BQ, Ting L, Zhang Y, Liu C (2018) Rheological properties of bentonite-free water-based drilling fluids with novel polymer viscosifier. J Petrol Sci Eng 164:302-310

Zhang L (2011) Study on the degradation and stability for flooding polymers. MS Thesis, University of Shandong

Publisher's Note Springer Nature remains neutral with regard to jurisdictional claims in published maps and institutional affiliations. 